\title{
HIV na gestação: pré-natal, parto e puerpério
}

\author{
HIV in pregnancy: prenatal, labor and puerperium
}

\section{Suzane da Silva de Limaa, Ludimila Cristina Souza Silva ${ }^{b}$, Michele Vidal dos Santosa, João Paulo Martinsa, Márcia Campos de Oliveiraa, Marislei Espindola Brasileiroc}

a Graduação em Enfermagem pela Faculdade Unida de Campinas.

b Enfermeira. Doutoranda em Ciência da Saúde FM-UFG. Docente da Faculdade Alfredo Nasser e da Faculdade Unida de Campinas.

c Enfermeira. Doutora em Ciências da Saúde FM-UFG. Docente da Faculdade Unida de Campinas.

RESUMO

Objetivo: O presente estudo tem como propósitos identificar os fatores que influenciam a adesão da gestante ao acompanhamento pré-natal e destacar os principais cuidados com a gestante soropositiva durante o pré-natal, parto e puerpério.

Materiais e Métodos: Trata-se de uma revisão integrativa da literatura, com análise baseada em níveis de evidências. Os dados foram obtidos através da busca em bases de dados virtuais em saúde.

Resultados: Treze estudos compuseram a amostra, sendo que o maior índice foi de evidências moderadas, seis $(46,1 \%)$ estudos. Os principais cuidados à gestante soropositiva durante o pré-natal, parto e puerpério foram: uso da terapia antirretroviral, evidenciado em sete (53,8\%) estudos, seguido do teste Anti-HIV e da preocupação em orientar as puérperas a não amamentar destacados em seis $(46,1 \%)$ estudos.

Conclusão: Torna-se necessária a implantação de uma assistência de qualidade às gestantes soropositivas, evidenciando a necessidade de estratégias de educação permanente para sensibilizar, mobilizar e capacitar profissionais envolvidos no cuidado, visando, assim, à prevenção da transmissão vertical do HIV para o recém-nascido e à melhora na qualidade de vida da gestante.

Palavras-chave: HIV; gravidez; transmissão vertical; assistência.

\section{ABSTRACT}

Objective: The present study aims to identify the factors that influence the adherence of pregnant woman to the prenatal care and to highlight the main care with the HIV-positive pregnant woman during prenatal, delivery and puerperium.

Materials and Methods: This is an integrative literature review, with levels of evidence-based analysis. Data were obtained by scanning in virtual databases in health.

Results: Thirteen studies were included in the sample. The highest index found was moderate evidence, in six (46.1\%) of the studies. The main care to HIV-positive pregnant women during the prenatal, delivery and postpartum period were: use of antiretrovial therapy, evidenced in seven (53.8\%) of the studies, followed by the Anti-HIV testing and the concern in guiding the mothers not to breastfeed, evidenced in six $(46.1 \%)$ of the studies.

Conclusion: It is necessary to implement quality care to HIV-positive pregnant women, highlighting the need for continuing education strategies to raise awareness, to mobilize and to train professionals involved in care, aiming at the prevention of vertical HIV transmission to the newborn and the improvement of the quality of life of pregnant women.

Keywords: HIV; pregnancy; vertical transmission; assistance. 


\section{INTRODUÇÃO}

A síndrome da imunodeficiência adquirida (AIDS) é uma doença crônica infecciosa, causada pelo vírus da imunodeficiência humana (HIV). Os primeiros casos de AIDS no Brasil ocorreram na década de 80, considerados uma epidemia que se alastrou rapidamente, tornando-se um problema de saúde pública'.

Acreditava-se que essa contaminação ocorria, apenas, em homossexuais, prostitutas, dependentes químicos e hemofílicos, que eram chamados de grupo de risco. Porém, a contaminação atingiu outros grupos chamados de feminilização que são mulheres de idade entre 20 a 34anos. Essa faixa etária de mulheres contaminadas tornouse preocupante, pois se encontram em idades férteis ocasionando um aumento de transmissão vertical da mãe para o recém-nascido².

A preocupação existente entre as gestantes com HIV é o risco de transmissão vertical para seu RN. A maioria da transmissão vertical ocorre durante o trabalho de parto com $65 \%$, outras ocorrem intraútero com $35 \%$, essencialmente nas últimas semanas de gestação e no aleitamento materno, representando um risco adicional de transmissão de $7 \%$ a $22 \%{ }^{3}$.

De acordo com o boletim epidemiológico do Ministério da Saúde, nos anos de 2013 e 2014 foram notificados 70.677 casos de infecção pelo vírus da imunodeficiência humana (HIV) entre adultos e 773, em crianças. Dessas notificações, 7.219 são de gestantes infectadas com vírus HIV. Nos últimos dez anos, observou-se uma tendência de queda estatisticamente significativa no Brasil com 35,7\% de contaminação da gestante com HIV para o RN 4 .

Essa significativa redução nas taxas de transmissão vertical é decorrente da conscientização das gestantes em realizar o pré-natal, no qual ocorrem o aconselhamento e incentivo para a realização do teste de HIV; a utilização precoce do tratamento com antirretrovirais; a orientação sobre a escolha da via de parto, a qual dependerá das situações obstétricas e/ou da carga viral; orientações no puerpério sobre a não adesão ao aleitamento materno e sobre os cuidados rotineiros, aumentando, assim, as chances da gestante ter um bebê saudável ${ }^{5}$.

O conhecimento do status sorológico da infecção pelo HIV e a precocidade do diagnóstico tornaram possível a interrupção da cadeia de transmissão, além de permitir uma atenção adequada às gestantes infectadas ${ }^{6}$. A taxa de incidência de HIV em gestantes no Brasil apresentou um aumento significativo nos últimos dez anos, de 2000 até 2014 foi de 84.558, porém a taxa de detecção de HIV, em menores de cinco anos, tem-se observado uma queda estatisticamente significativa na transmissão vertical no Brasil, cerca de $35,7 \%$ respectivamente de 2004 a $2013^{7}$.

Diante disso, torna-se de grande relevância estudos que possam evidenciar a importância da atuação da equipe multiprofissional para garantir às gestantes soropositivas um pré-natal, parto e puerpério de qualidade, evitando a contaminação do recém-nascido. Portanto, o objetivo deste estudo é ter como propósitos identificar os fatores que influenciam a adesão da gestante ao acompanhamento pré-natal e destacar os principais cuidados com a gestante soropositiva durante o pré-natal, parto e puerpério.

\section{MATERIAIS E MÉTODOS}

Trata-se de uma revisão integrativa da literatura, a qual se refere a um método que analisa e resume as pesquisas de maneira sistematizada e contribui para aprofundamento do tema investigado e, a partir dos estudos realizados separadamente, é possível construir uma única conclusão, pois foram investigados problemas idênticos ou parecidos ${ }^{8}$. A questão norteadora do presente estudo foi: Qual o papel da equipe multiprofissional e os principais cuidados com a gestante soropositiva durante o pré-natal, parto e puerpério?

O estudo foi realizado por meio de busca on-line das produções científicas nacionais sobre HIV na gestação, prénatal, parto e puerpério, no período de 2007 a 2014. A obtenção dos dados ocorreu através de buscas processadas por meio da Biblioteca Virtual em Saúde (BVS), sendo utilizadas principalmente as bases de dados: Literatura Latino-Americana e do Caribe em Ciências da Saúde (LILACS), Scientific Eletronic Library Online (SciELO). Os descritores utilizados para a busca foram: HIV, Gravidez, Transmissão Vertical, Cuidados pré-natal.

Para a realização de uma pesquisa bibliográfica de qualidade, o primeiro passo é localizar a terminologia autorizada e reconhecida mundialmente. O descritor controlado é parte de um vocabulário estruturado e organizado para facilitar o acesso à informação. Esses vocabulários são usados como uma espécie de filtro entre a linguagem utilizada pelo autor e a terminologia da área9.

Foram considerados os seguintes critérios de inclusão: estudos que abordem o HIV na gestação, os principais cuidados com a gestante com HIV e a importância do tratamento e acompanhamento adequado das gestantes com HIV para evitar possíveis complicações à criança; publicados no idioma português. Foram excluídos artigos que não responderam à pergunta norteadora.

$\mathrm{O}$ acesso à base de dados e a coleta de dados foram realizados em junho de 2015. Em seguida, todos os estudos foram lidos na íntegra. Por meio dos descritores foram 
identificados 329 estudos, sendo selecionados 13 que atenderam aos critérios de inclusão estabelecidos.

Após a leitura na íntegra de cada um dos artigos, foi preenchido um instrumento, elaborado pelos autores no Microsoft Word 2010, contendo os seguintes itens: identificação do artigo, ano e país de publicação, idioma, tipo de instituição onde foi realizado o estudo, metodologia empregada e o nível de evidência e identificação da adesão das gestantes soropositivas ao tratamento precoce; analise de dados epidemiológicos que mostraram o quantitativo de gestantes soropositivo; destaque do papel da equipe multiprofissional no pré-natal da gestante soropositiva; identificação dos principais cuidados com a gestante soropositiva durante o pré-natal, parto e puerpério; conhecimento do cuidado puerperal que a gestante deve ter com seu RN.

A avaliação do nível de evidência foi classificada em: Nível 1 - revisões sistemáticas ou metanálise de relevantes ensaios clínicos; Nível 2 - evidências derivadas de, pelo menos, um ensaio clínico randomizado, controlado, bem delineado; Nível 3 - ensaios clínicos bem delineados sem randomização; Nível 4 - estudos de coorte e de casocontrole bem delineados; Nível 5 - revisão sistemática de estudos descritivos e qualitativos; Nível 6 - evidências derivadas de um único estudo descritivo ou qualitativo e Nível 7 - opinião de autoridades ou relatório de comitês de especialistas. As evidências pertencentes aos níveis I e II são consideradas fortes, de III a V, moderadas e VI e VII, fracas $^{10}$.

\section{RESULTADOS}

Foram encontrados 329 artigos, porém somente 13 foram utilizados, pois atenderam aos critérios de inclusão do estudo. $\mathrm{O}$ ano em que mais houve publicações foi o ano 2008 com quatro $(28,57 \%)$ e o ano que teve menor índice de publicação foi 2007 com um (7,1\%). Percebe-se que o índice de publicações teve aclive no transcorrer dos tempos. O periódico que mais publicou foi a Revista da Escola Ana Nery Enfermagem com três (23.0\%).

Quanto á metodologia de pesquisa utilizada nos estudos a que prevaleceu foi os ensaios clínicos delineados, sem randomização, presentes em seis $(46,1 \%)$ estudos. Quanto ao nível de evidências, três $(23,1 \%)$ estudos pertencem aos níveis I e II que são considerados evidências fortes, seis $(46,1 \%)$ foram considerados de nível III a V, ou seja, moderados e quatro (30,8 \%) estudos VI e VII considerados, fracas. Portanto, o que prevaleceu foram estudos de evidências moderadas.

A Tabela 1 apresenta a distribuição dos estudos que foram publicados no Brasil quanto ao ano, autor e periódico.
A distribuição dos estudos quanto aos fatores que impedem a adesão das gestantes soropositivas às estratégias assistenciais no pré-natal, parto e puerpério são apresentados na Tabela 2. Falta de acesso aos serviços de saúde, medo do preconceito e falta de capacidade profissional foram destacados em quatro $(30,7 \%)$ estudos como fatores que impedem a adesão das gestantes soropositivas às estratégias assistenciais no prénatal, parto e puerpério.

Tabela 1. Distribuição dos estudos que foram publicados no Brasil quanto ao ano, autor e periódico.

\begin{tabular}{ccll}
\hline $\begin{array}{c}\text { Estudos } \\
\text { analisados }\end{array}$ & Ano & \multicolumn{1}{c}{ Autor } & \multicolumn{1}{c}{ Periódico } \\
\hline 1 & 2007 & Cechim et al. & Rev Bras Enferm. \\
2 & 2008 & Araújo et al. & Ciênc Saúde Coletiva \\
3 & 2008 & Cavalcante et al. & Rev. Bras Saude Mater Infant. \\
4 & 2008 & Silva et al. & Esc Anna Nery \\
5 & 2009 & Scherer et al. & Esc Anna Nery \\
6 & 2010 & Carneiro \& Coelho & Ciênc Saúde Coletiva \\
7 & 2010 & Darmont et al. & Cad. Saúde Pública \\
8 & 2012 & Araújo et al. & Esc Anna Nery \\
9 & 2013 & Passos et al. & Rev Bras Epidemiol. \\
10 & 2013 & Teixeira et al. & Rev Pesqui Cuid Fundam \\
11 & 2014 & Faria et al. & Psic: Teor Pesq. \\
12 & 2014 & Tirado et al. & Rev Bras Ginecol Obstet. \\
13 & 2014 & Kleinubing et al. & Rev Enferm UFPE on line \\
\hline
\end{tabular}

Tabela 2. Distribuição dos estudos quanto aos fatores que impedem a adesão das gestantes soropositivas às estratégias assistenciais no prénatal, parto e puerpério.

\begin{tabular}{llc}
\hline $\begin{array}{c}\text { Fatores que impedem a adesão das } \\
\text { gestantes soropositivas ás estratégias assistenciais } \\
\text { no pré-natal, parto e puerpério }\end{array}$ & $\mathbf{n}$ & $\%$ \\
\hline Falta de acesso aos serviços de saúde & 4 & 30,7 \\
Medo do preconceito & 4 & 30,7 \\
Falta de capacitação profissional & 4 & 30,7 \\
Baixo nível socioeconômico e de escolaridade & 3 & 23,0 \\
Falta no aconselhamento pré e pós-testes & 3 & 23,0 \\
Falta de qualidade do pré-natal & 2 & 15,3 \\
Aceitação da gestação & 2 & 15,3 \\
Dificuldade no acesso ao teste anti-HIV & 1 & 7,6 \\
\hline
\end{tabular}

A Tabela 3 reporta a distribuição dos estudos quanto aos principais cuidados implementados pela equipe multiprofissional à gestante soropositiva durante o pré-natal, parto e puerpério. Alguns cuidados são primordiais à gestante soropositiva, uma vez que o uso da terapia antirretrovial é evidenciado em sete $(53,8 \%)$ estudos, seguido do teste Anti-HIV e da preocupação em orientar as puerperas a não amamentar foram destacados em seis $(46,1 \%)$ estudos. 
Dados referentes a distribuição dos estudos quanto aos benefícios da adesão da gestante soropositiva aos cuidados no pré-natal, parto e puerpério constam na Tabela 4. A prevenção da transmissão vertical foi apresentada em cinco $(38,4 \%)$ estudos como sendo o principal benefício da adesão à gestante soropositiva aos cuidados no pré-natal, parto e puerpério.

Tabela 3. Distribuição dos estudos quanto aos principais cuidados implementados pela equipe multiprofissional à gestante soropositiva durante o pré-natal, parto e puerpério.

\begin{tabular}{llc}
\hline \multicolumn{1}{c}{$\begin{array}{c}\text { Cuidados à gestante soropositiva durante } \\
\text { o pré-natal, parto e puerpério }\end{array}$} & n & $\%$ \\
\hline Uso da terapia antirretroviral & 7 & 53,8 \\
Teste anti-HIV & 6 & 46,1 \\
Não amamentação & 6 & 46,1 \\
Parto cesário & 4 & 30,7 \\
Aconselhamento pré e pós-testes & 4 & 30,7 \\
Uso de quimioprofilaxia com AZT pelo bebê & 4 & 30,7 \\
Uso de quimioprofilaxia pelas gestantes soropositivas & 4 & 30,7 \\
na hora do parto & 2 & 15,3 \\
Acolhimento & 2 & 15,3 \\
Uso de preservativos nas relações sexuais & 2 & 15,3 \\
Grupos de apoio & 1 & 7,6 \\
\hline Preparo e fornecimento de fórmula infantil & & \\
\hline
\end{tabular}

Tabela 4. Distribuição dos estudos quanto aos benefícios da adesão da gestante soropositiva aos cuidados no pré-natal, parto e puerpério.

\begin{tabular}{llc}
\hline $\begin{array}{l}\text { Benefícios da adesão da gestante soropositiva } \\
\text { aos cuidados no pré-natal, parto e puerpério }\end{array}$ & n & $\%$ \\
\hline $\begin{array}{l}\text { Prevenção da transmissão vertical durante o parto } \\
\text { Autocuidado durante o pré-natal e o puerpério }\end{array}$ & 5 & 38,4 \\
$\begin{array}{l}\text { Melhor qualidade de vida durante pré-natal, parto e } \\
\text { puerpério }\end{array}$ & 2 & 15,3 \\
\hline
\end{tabular}

\section{DISCUSSÃO}

Os fatores que impedem a adesão das gestantes soropositivas aos cuidados durante o pré-natal, parto e puerpério foram a falta de acesso aos serviços de saúde, apresentado em quatro (30,7\%) estudos, e a dificuldade no acesso ao teste Anti-HIV, evidenciado em um $(7,6 \%)$ estudo, no qual o problema de acesso a gestantes soropositivas ao serviço de saúde inclue fatores socioeconômico e demográfico que impedem o acesso ás consultas do pré-natal, consequentemente, atrapalham a adesão ao tratamento e dificultam o acesso ao teste anti-HIV pela escassez de laboratórios, com isso coloca-se, em risco, o acompanhamento para prevenção da transmissão vertical ${ }^{1,11-13}$.

O medo do preconceito foi identificado em quatro $(30,7 \%)$ estudos, e a aceitação da gestação, em dois $(15,3 \%)$ estudos. Percebe-se que algumas mulheres gestantes soropositivas tiveram problemas na aceitação da gestação, pois não planejavam engravidar pela sua condição clínica e por não apresentarem condição financeira que permitissem a continuidade da gestação e, por isso, até pensavam em abortar $^{1,11}$.

O medo de preconceito e discriminação surge pela existência da patologia e chega a despertar, na gestante, o sentimento de vergonha em procurar o serviço de saúde para a realização do teste. Diante disso, é importante que as equipes de saúde desenvolvam estratégias que possam sensibilizar a população sobre a necessidade de realizar os testes e o acompanhamento da gestante para evitar a transmissão vertical $\left.\right|^{5,11,12,14}$.

A falta de capacitação dos profissionais foi destacada em quatro $(30,7 \%)$ estudos, pois muitos profissionais não sabem lidar com a realidade e as complexidades do HIV/ADIS, apresentam grande dificuldade de comunicação e falta de clareza na linguagem, fato que interfere, significativamente, na qualidade da assistência prestada ao usuário 3,12,13,15.

Quanto à inexistência do aconselhamento da importância dos pré e pós-testes, três (23\%) estudos mostraram que os profissionais não estão preparados para realizar um aconselhamento individual e/ou coletivo. A falta de aconselhamento acarreta problemas de saúde pública, pois, nesse momento, informações sobre a importância do acompanhamento da gestante e do bebê devem ser destacadas com o intuito de conscientizar os pacientes s, $^{3,12}$. A falta de qualidade no atendimento ao pré-natal foi destacada em dois $(15,3 \%)$ estudos, mostrando que a baixa procura pelo acompanhamento durante o pré-natal encontra-se associada a falhas no aconselhamento e a rotatividades dos profissionais ${ }^{11,15}$.

O baixo nível socioeconômico e de escolaridade foi destacado em três $(23,0 \%)$ estudos, como sendo responsável pela adesão das gestantes soropositivas desde o aconselhamento até o acompanhamento no pré-natal. Muitas vezes, as gestantes não apresentam condições financeiras para comparecerem ás unidades de saúde para a realização do aconselhamento pré e pós-testes, não comparecem ao laboratório para a realização do teste anti-HIV e o acompanhamento do pré-natal. E a falta de escolaridade dificulta a busca por informações e impede a compreensão sobre a importância de se realizar o teste e o acompanhamento $0^{1,3,14}$.

Dentre os principais cuidados implementados pela equipe multiprofissional á gestante soropositiva, a utilização de Grupos de Apoio foi destacada como uma estratégia de impacto em dois (15,3\%) estudos, nos quais a equipe de saúde ajuda as gestantes soropositivas a desenvolverem 
estratégias de enfrentamento da doença através de apoio psicológico $^{2,12}$.

O acolhimento foi evidenciado em dois (15,3\%) estudos, como uma medida necessária para garantir a interação entre a gestante soropositiva e a equipe de saúde, com o intuito de promover a superação dos desafios enfrentados pela gestante através de orientação e informações positivas capazes de resolver ou amenizar suas angústias ${ }^{11,16}$.

Através de portarias e normas técnicas, o Ministério da Saúde vem estabelecendo medidas para o aperfeiçoamento das ações para o controle e redução da transmissão de HIV no país. As medidas disponibilizam testes rápidos e exames de seguimento, medicações antirretrovirais e materiais técnicos que possibilitam aos profissionais prestarem orientações e darem suporte ás gestantes com HIV ${ }^{15}$.

A adesão ao uso da Terapia Antirretroviral foi evidenciado em sete $(53,8 \%)$ estudos, como uma estratégia que possibilita a diminuição significativa da carga viral, com isso aumenta a possibilidade de engravidar pelo fato de superar o medo de transmitir o vírus para o bebê. $\mathrm{O}$ uso da terapia antirretroviral é de suma importância, pois, além de ser uma forma de prevenir a transmissão vertical do HIV, possibilita que a gestante tenha uma boa qualidade de vida5,12,15-18,

A administração da quimioprofilaxia com AZT pelas gestantes soropositivas na hora do parto foi evidenciada em quatro (30,7\%) estudos. Sua via de administração é por via intravenosa e é administrada independente do nível da carga viral mesmo podendo apresentar 1.000 cópias $/ \mathrm{ml}$, sendo capaz de reduzir significativamente a carga plasmática do HIV para níveis indetectáveis. Tornando-se um importante meio de prevenção contra a transmissão vertical do HIV5,15,12,16.

Uso de preservativos nas relações sexuais foi evidenciado em dois (15,3\%) estudos o qual apresentou-se como um cuidado aconselhado pela equipe de saúde para que possa diminuir o aparecimento de doenças oportunistas ${ }^{2,5}$. A realização do Teste Anti-HIV foi apresentada por seis $(43,1 \%)$ estudos, como sendo a primeira etapa de prevenção da transmissão vertical do HIV, já que, logo após a confirmação da doença, a gestante deve ser orientada sobre os cuidados e tratamentos. É preconizado que esse exame seja feito pela gestante logo na primeira consulta de pré-natal, porém muitas gestantes ainda têm uma resistência para realizar o exame, demonstrando receios em descobrir sua condição sorológica, caso seja positiva 3 3, 13,14,16,17.

A escolha do tipo de parto que será realizado em parturiente soropositivo dependerá do nível de sua carga viral, sendo que, em quatro (30,7\%) estudos, o parto Cesário foi destacado como o mais recomendado e seguro, pois o risco de transmissão vertical para o RN é mínimo $5,12,15,17$.
A não amamentação foi destacada em seis $(46,1 \%)$ estudos, como um meio de prevenção da transmissão vertical do HIV, pois o vírus está presente no leite materno. A inibição da lactação deve ser feita imediatamente após o parto, através, principalmente, da administração de medicações para cessar a produção de leite materno ${ }^{5,12,15-17}$. Em decorrência da inibição da lactação é necessário fornecer suplementação ao recém-nascido. A fórmula infantil foi apresentada em um $(7,6 \%)$ estudo como uma importante estratégia para suprir as necessidades alimentícias do recémnascido $^{16}$

A prevenção da transmissão vertical do HIV foi destacada em cinco $(38,4 \%)$ estudos, como um benefício à adesão da gestante soropositiva aos cuidados no pré-natal, parto e puerpério. É importante a realização de cuidados orientados pela equipe de saúde, desde a fase do pré-natal, parto e puerpério, pois, através dessas medidas e cuidados, é possível a prevenção da transmissão vertical do HIV para o recém-nascido ${ }^{12,15,16,19}$

O enfrentamento da doença, medidas profiláticas e o apoio recebido de familiares e da sociedade levam as gestantes soropositivas a ter controle de sua vida e consequentemente, aumentam sua expectativa e qualidade de vida, pois dois (15,3\%) estudos corroboram essa ideia ${ }^{12,18}$. Com o aumento da qualidade de vida e a diminuição do risco da transmissão vertical do HIV ao RN, aumentou-se o desejo de engravidar, já que muitas gestantes soropositivas relataram que a gravidez é um momento esperado por muitas mulheres, dando-lhes, assim, expectativa de gerar um bebê saudável ${ }^{17}$.

O autocuidado foi evidenciado em três (23.0\%) estudos, como benefícios ás gestantes com HIV, pois são sensibilizadas pela equipe de saúde a satisfazer as necessidades do corpo e da mente, melhorar o estilo de vida, evitar hábitos nocivos, desenvolver uma alimentação sadia, conhecer e controlar os fatores de risco que levam às doenças e adotar medidas de prevenção de doenças ${ }^{2,11,18}$.

Percebe-se que a maioria das gestantes é diagnosticada com HIV, durante o período gestacional, e nesse período, o aconselhamento e o teste anti-HIV são essenciais e integram os cuidados no pré-natal. Porém, muitos profissionais ainda não são capacitados e preparados para realizar o aconselhamento. A partir da confirmação da soropositividade, a equipe de saúde deve prestar uma assistência específica às gestantes contaminadas. A assistência terá como objetivo o controle da carga viral e, consequentemente, a redução dos riscos da transmissão vertical do HIV para o bebê.

Entretanto, é necessário que os profissionais de saúde ofereçam uma assistência de qualidade ás gestantes soropositivas, o que justifica a necessidade da qualificação do 
profissional nesse contexto. É necessária á implementação de estratégias de educação permanente que possam sensibilizar, mobilizar e capacitar profissionais envolvidos com essa assistência. Por isso, é de suma importância, que as gestantes com HIV sintam-se acolhidas nos serviços de saúde e tenham conhecimento para tomada de decisões com responsabilidades, visando á sua qualidade de vida e á segurança do recém-nascido. Portanto, só assim tornarão possíveis a conscientização e a elaboração de estratégias preventivas que promovam a redução da transmissão vertical do HIV de mãe para filho.

\section{REFERÊNCIAS}

1. Cechim PL, Perdomini FRI, Quaresma LM. Gestantes HIV positivas e sua não-adesão à profilaxia no pré-natal. Rev Bras Enferm. 2007;60(5):519-23. https://doi.org/10.1590/S003471672007000500007

2. Scherer LM, Borenstein MS, Padilha MI. Gestantes/puérperas com hiv/aids: conhecendo os déficits e os fatores que contribuem no engajamento para o autocuidado. Esc Anna Nery. 2009;13(2): 359-65. https://doi.org/10.1590/S1414-81452009000200017

3. Passos SCS, Oliveira MIC, Gomes Junior SCS, Silva KS. Aconselhamento sobre o teste rápido anti-HIV em parturientes. Rev Bras Epidemiol. 2013;16(2):278-87. https://doi.org/10.1590/ S1415-790X2013000200005

4. Ministério da Saúde (BR). Boletim epidemiológico Aids e DST. Brasília: Ministério da Saúde; 2014

5. Silva RMO, Araújo, CLF, Paz FMT. A realização do teste antihiv no pré-natal: os significados para a gestante. Esc Anna Nery. 2008;12(4):630-6. https://doi.org/10.1590/S141481452008000400004

6. Ministério da Saúde (BR). Secretaria de Vigilância em Saúde. Recomendações para profilaxia da transmissão vertical do HIV e terapia antirretroviral em gestantes [Internet]. Brasília: Ministério da Saúde; 2010 [cited 2015 Jul 20]. Available from: http://www.ensp. fi ocruz.br/portal-ensp/judicializacao/pdfs/490.pdf

7. Ministério da Saúde (BR). Departamento de DST, AIDS e Hepatites virais [Internet]. Portaria № 1.271, de 6 de junho de 2014. [cited 2015 Out 10]. Available from: http://www.suvisa.ba.gov.br/sites/ default/files/vigilancia_epidemiologica/doencas_transmissiveis/ arquivo/2014/07/11/Instru\%C3\%A7\%C3\%A30\%20normativa notifica $\%$ C3\%A7\%C3\%A3oHIV.pdf

8. Mendes KDS, Silveira RC, Galvão CM. Revisão Integrativa: método de pesquisa para a incorporação de evidências na saúde e na enfermagem. Texto Contexto Enferm. 2008;17(4):758-64. https:// doi.org/10.1590/S0104-07072008000400018

9. Pellizzon RF. Pesquisa na área da saúde: 1 - base de dados DeCS (Descritores em Ciências da Saúde). Acta Cir Bras. 2004;19(2): 153-63. https://doi.org/10.1590/S0102-86502004000200013

10. Milani RN, Canini SRMS, Garbin LM, Teles AS, Gir E, Pimenta FR. Imunização contra hepatite B em profissionais e estudantes da área da saúde: revisão integrativa. Rev Eletr Enf. 2011;13(2):323-30. https://doi.org/10.5216/ree.v13i2.12151

11. Darmont MQR. Martin HS, Calvet GA, Deslandes SF, Menezes JA. Adesão ao pré-natal de mulheres HIV + que não fizeram profilaxia da transmissão vertical: um estudo sócio-comportamental e de acesso ao sistema de saúde. Cad. Saúde Pública. 2010;26(9): 1788-96. https://doi.org/10.1590/s0102-311×2010000900012

12. Faria ER. Gestação e HIV: preditores da adesão ao tratamento no contexto do pré-natal. Psic: Teor Pesq. 2014;30(2):197-203. https:// doi.org/10.1590/s0102-37722014000200009

13. Araújo MAL, Vieira NFC, Silva RM. Implementação do diagnóstico da infecção pelo HIV para gestantes em Unidade Básica de Saúde da Família em Fortaleza, Ceará. Ciênc Saúde Coletiva. 2008;13(6):18991906. https://doi.org/10.1590/S1413-81232008000600025

14. Carneiro AJS, Coelho EAC. Aconselhamento na testagem anti-HIV no ciclo gravídico-puerperal: o olhar da integralidade. Ciênc Saúde Coletiva. 2010;15(1):1216-26. https://doi.org/10.1590/S141381232010000700031

15. Cavalcante MS. Prevenção da transmissão vertical do vírus da imunodeficiência humana: análise da adesão às medidas de profilaxia em uma maternidade de referência em Fortaleza, Ceará, Brasil. Rev. Bras Saude Mater Infant. 2008;8(4):473-9. https://doi. org/10.1590/S1519-38292008000400013

16. Araújo CLF, Signes AF, Zampier VS. B. O cuidado à puérpera com HIV/AIDS no alojamento conjunto: a visão da equipe de enfermagem. Esc. Anna Nery. 2012;16(1):49-56. https://doi. org/10.1590/S1414-81452012000100007

17. Teixeira SVB, Silva GS. Women living with hiv: the decision to become pregnant. Rev Pesqui Cuid Fundam. (Online). 2013;5(1):3159-67. https://doi.org/10.9789/2175-5361.2013v5n1p3159

18. Tirado MCBA, Bortoletti FF, Nakamura UM, Souza E, Soárez PC, Castelo Filho A, Amed AM. Qualidade de vida de gestantes infectadas pelo vírus da imunodeficiência humana (HIV) na cidade de São Paulo. Rev Bras Ginecol Obstet. 2014;36(5):228-32. https:// doi.org/10.1590/S0100-7203201400050008

19. Kleinübing RE, Lipinski JM, Pereira FW, Fonseca AD, Chagas MCS, Ilha S. Puerperas soropositivas para o HIV: como estão vivenciando a não amamentação. Rev Enferm UFPE on line. 2014;8(1):107-13. 